\title{
The indirect relationship between personality and performance through job crafting behaviour
}

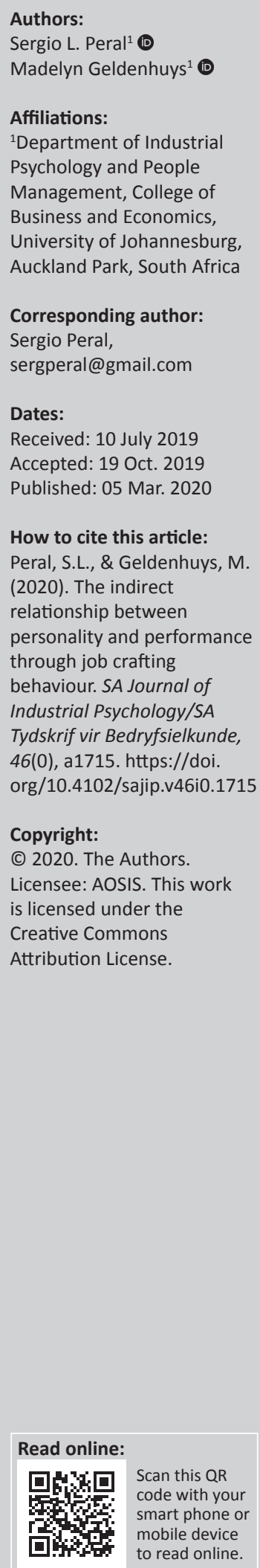

Orientation: Individual personality is known to have a direct impact on job performance. Yet, little is known about the behavioural processes through which personality unfolds and ultimately affects employee performance.

Research purpose: This study set out to investigate the indirect relationship between personality and performance through job crafting behaviour. Job crafting, the proactive changes employees make to their task, relational and cognitive job boundaries, has been shown to relate to a number of positive employee and organisational outcomes.

Motivation for the study: Individual differences, such as personality, affect the manner in which employees approach their work, be it in the tasks they complete or the relationships that they build with others. It is thus imperative to understand how unique personality traits have an impact on important business outcomes such as job performance.

Research approach/design and method: A quantitative cross-sectional research design was conducted amongst a sample of South African working individuals $(N=580)$. Structural equation modelling (SEM) was the primary statistical technique used to investigate the research hypotheses.

Main findings: The study results showed that the 'Big Five' personality traits indirectly influenced job performance (i.e. in-role behaviour, organisational citizenship behaviour) through job crafting as a mediator.

Practical/managerial implications: Organisations who take the initiative to truly understand their employees and their unique personalities have a greater chance of leveraging valuable employee and business outcomes such as job crafting and job performance. Incorporating valid and reliable personality measures in an organisation's recruitment and selection process may thus prove beneficial in predicting proactive work behaviours and overall employee performance.

Contribution/value-add: This study contributes to the limited knowledge surrounding the individual antecedents of job crafting behaviour and further shows how one's predisposition (i.e. personality) can have an indirect impact on performance through the behaviours employees engage in, such as job crafting.

Keywords: Big Five; Five-Factor Model; job crafting; in-role behaviour; organisational citizenship behaviour.

\section{Introduction}

Personality pervades us in our everyday life, influencing individuals' career choices (Furnham, 2002), working styles (Hoekstra, 1993), engagement levels (Woods \& Sofat, 2013) and their ability to react to and interact with others (De Janasz, Dowd, \& Schneider, 2002). Oldham and Fried (2016) recently came to the consensus that employees respond differently to their job characteristics as a function of their underlying personality traits. Personality research further shows that one's personality can affect attitudes towards work (Palaiou, Zarola, \& Furnham, 2016), experienced levels of fit to the job (Ehrhart, 2006) and, most importantly, job performance (Barrick \& Mount, 1991; Mount, Barrick, \& Stewart, 1998). Previous studies have yielded important information regarding the personalityperformance relationship. Meta-analytic findings, for example, reveal that certain personality traits (i.e. extraversion and agreeableness) are important for successful job performance in occupations requiring high levels of social interaction, such as sales (Barrick \& Mount, 1991).

Previous research predominantly looked at the direct personality-performance relationship, with little attention being given to the indirect ways in which personality may affect performance. 


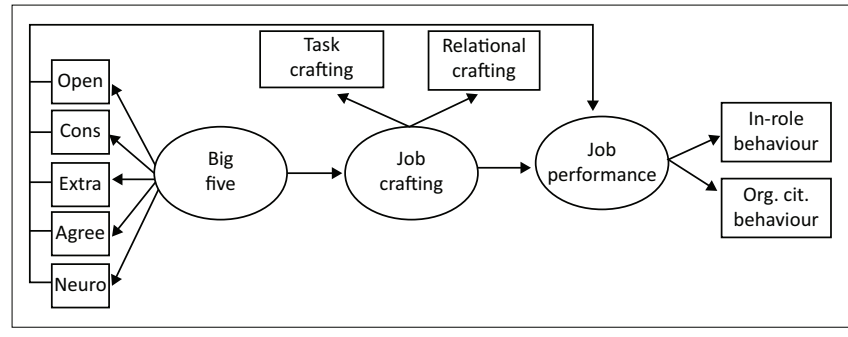

Org. cit., organisational citizenship behaviour.

FIGURE 1: Hypothesised research model.

Concurring with the notion that personality is an indirect determinant (Johnson \& Schneider, 2013), this study proposes that job crafting - a proactive type of employee behaviour that involves altering one's physical and cognitive job boundaries (Wrzesniewski \& Dutton, 2001) - mediates the relationship between personality and performance. That is, it is believed that employees engage in different types of job crafting behaviours as a result of their underlying personality traits, which, in turn, affect their performance. It is important to understand why and to what extent personality traits influence employees' willingness to craft their jobs, as job crafting positively influences positive workplace outcomes such as job performance (Gordon, Demerouti, Le Blanc, \& Bipp, 2015; Tims, Bakker, \& Derks, 2015).

Using a series of structural equation models, the aim of this research was to explore individuals' personality traits as antecedents to job crafting behaviour and its subsequent implications on one's job performance. In particular, this study investigates the indirect relationship between the 'Big Five' personality traits and job performance through job crafting behaviour. The hypothesised research model is presented in Figure 1.

\section{Job crafting}

Job crafting is a promising workplace strategy that employees can use to increase their work-related well-being (Tims et al., 2015). An employee is said to be engaged in job crafting when he or she physically changes the manner in which he or she performs the job (e.g. increasing or decreasing the amount of social interaction with co-workers) and mentally changes the manner in which he or she perceives the job (e.g. seeing the job as an integral part to the organisation as opposed to just a 'job'). Employees will engage in job crafting activities to make work more meaningful to them by changing the task (changing the type or amount of work employees do), relational (deciding how employees interact with colleagues) and cognitive (changing personal perspective about their work) boundaries of their work (Slemp \& Vela-Brodrick, 2013; Wrzesniewski \& Dutton, 2001). Given that job crafting has important implications for employee well-being and performance (Gordon et al., 2015; Tims et al., 2015), it is imperative that organisations understand the factors that drive or predict such behaviour. In contrast to its workrelated outcomes, there is a shortage of research surrounding the individual antecedents of job crafting, with calls being made to examine the personal conditions that encourage or promote job crafting behaviour (Oldham \& Fried, 2016; Vogt, Hakanen, Brauchli, Jenny, \& Bauer, 2016; Wrzesniewski \& Dutton, 2001). Employees may also choose to craft their tasks, relationships and cognitions to exert control over their work, to maintain a good self-image and to connect with others (Wrzesniewski \& Dutton, 2001). It is for this reason that the task, relational and cognitive crafting conceptualisation is expected to align closely with personality.

\section{The Five-Factor Model}

The Five-Factor Model (FFM) (Tupes \& Christal, 1961), commonly referred to as the 'Big Five' (Goldberg, 1990), is a hierarchical organisation of personality whose structure is considered universal (McCrae \& Costa, 2008). There are five factors subsumed with the FFM, namely, extraversion, agreeableness, conscientiousness, neuroticism and openness to experience (McCrae \& Costa, 1997).

Extraverts are energised by social interactions and seen as outgoing, social and friendly (McCrae \& Costa, 1997). Agreeable individuals have the tendency to be nurturing, caring, emotionally supportive, trustful and good-natured (Digman, 1990; John \& Srivastava, 1999). Conscientiousness is characterised by the tendency to be punctual, hardworking, well organised, careful and thorough (Colbert, Mount, Harter, Witt, \& Barrick, 2004). Neuroticism, or low emotional stability, refers to the tendency to experience negative emotions and the behaviours that accompany them (McCrae \& Costa, 2008). Highly neurotic individuals are generally stressed, anxious, impulsive and vulnerable (Ones \& Viswesvaran, 2001) and as a result display ineffective coping and poor emotional adjustment strategies (Judge \& Ilies, 2002; McCrae \& Costa, 1997). Finally, openness to experience, or what is also known as intellect, culture or creativity (cf. Digman, 1990), refers to the tendency to be aesthetically sensitive, creative, open-minded and cultured.

These individuals like to explore new things, have wide interests and imaginations, and display unusual thought processes (McCrae \& Costa, 2008).

\section{Job performance}

The FFM, as a taxonomy of personality, has been used to explain individual differences in job performance (e.g. Barrick \& Mount, 1991; Rothman \& Coetzer, 2003). As a concept, job performance refers to the actions or behaviours that individuals engage in at work that contribute towards the overall functioning of the organisation (Campbell \& Wiernik, 2015). Rothman and Coetzer (2003) define job performance as the initiative and resourcefulness employees display in completing their job tasks and solving workrelated problems, as well as the efficiency with which they fulfil such responsibilities. The accumulation of research findings over the years has led to the general consensus that job performance is a multidimensional construct consisting of two distinct groups of behaviour that each independently contribute to overall job performance, namely, 
task performance and contextual performance (Borman \& Motowidlo,1997; Koopmans et al., 2011; Motowidlo \& Van Scotter, 1993; Rotundo \& Sackett, 2002). The different conceptualisations of job performance therefore consider how employees contribute towards the organisation's goals by helping the organisation reach individual (task or in-role) and organisational (contextual or extra-role) goals, which makes the job performance model of Williams and Anderson (1991) so useful in determining organisational citizenship behaviours because it investigates task (in-role) and contextual (extra-role) performance, respectively.

Task performance, also known as in-role behaviour (IRB) (Williams \& Anderson, 1991), regards those behaviours that are role-prescribed (Katz \& Kahn, 1978), sanctioned and formally recognised and rewarded by the organisation. These behaviours are stipulated in the incumbent's job description and are necessary for the day-to-day functioning of the organisation. According to Motowidlo and Van Scotter (1993), task performance refers to behaviours that transform raw materials into goods and services produced or offered by the organisation. Formally stated, they involve the execution of technical processes that contribute to the organisation's technical core (Motowidlo \& Van Scotter, 1993). Examples of task performance for a salesperson may include closing a business deal, having adequate product knowledge and effectively managing their time on the job (cf. Organ, Podsakoff, \& Podsakoff, 2011).

On the other hand, when an individual goes beyond what is required of the job, we say that they are engaged in contextual performance, or what others regard as organisational citizenship behaviour (OCB) or extra-role behaviour (Organ, 1988; Williams \& Anderson, 1991). Contextual performance, or OCB, is defined as those voluntary actions or activities that are not recognised by the formal reward system. OCBs shape the organisational, social and psychological contexts which promote the efficient and effective functioning of the organisation (Organ, 1988; Organ et al., 2011). There are two forms of OCB: those targeted towards a specific individual, co-worker or supervisor (i.e. OCB-I) and those that are more impersonal in nature and aim to benefit the larger organisation (i.e. OCB-O) (Organ et al., 2011).

Examples of OCBs include volunteering to take on additional work not part of the formal job requirements, helping and cooperating with others, and demonstrating conscientiousness in support of the organisation (e.g. saying good things about the organisation to outsiders) (Borman \& Motowidlo, 1997).

\section{Five-Factor Model, job crafting and job performance}

According to Tims and Kooij (2015), the proactive changes employees make to their jobs in the form of job crafting behaviour may contribute to improved job performance. It is understandable to think why this is such, because changing the design of the job to better suit the skills, preferences and needs of the job holder may lead to an enhanced work experience and ultimately better performance. Indeed, researches have established a positive relationship between job crafting and job performance across a range of occupations, including teachers (Leana, Applebaum, \& Schevchuk, 2009) and healthcare professionals (Gordon et al., 2015; Tims, Bakker, Derks, \& Van Rhenen, 2013). Tims et al. (2015), in a recent longitudinal investigation, found that job crafting had a positive indirect relationship with IRB through the mediational process of work engagement. These findings were further supported by Wesler and Niessen (2016) who found that employees who crafted their work by extending their task and relational boundaries reported higher scores on task performance (self-ratings).

It is evident that a relationship indeed exists between job crafting and job performance (see Lichtenthaler \& Fischbach, 2018; Rudolph, Katz, Lavigne, \& Zacher, 2017). Further, researches mainly focus on how employees make specific changes to their job characteristics (i.e. increasing challenging demands and social relations and decreasing hindering demands) (Rudolph et al., 2017), whilst we know little about how employees change their job perceptions (their tasks, relationships and cognitions at and of work) (see Slemp \& Vela-Broderick, 2013; Wrzesniewski \& Dutton, 2001). We address this gap by investigating task, relational and cognitive crafting and their unique relationships with different job performance criteria.

Using the conceptualisation of job crafting according to Wrzesniewski and Dutton (2001) as well as Slemp and VelaBrodrick (2013), we anticipate that task crafting will relate positively with task performance (i.e. IRB) as individuals who change the physical design of their jobs through task crafting should experience a better fit between their personal characteristics and the characteristics of the job itself, which will aid them in completing their in-role activities more proficiently. Individuals who score high on task crafting are also more likely to find new and creative ways to carrying out their work tasks which could result in better task performance. In terms of relational crafting, it is expected that there will be a positive relationship between relational crafting and OCB-I. Individuals who score high on relational crafting enjoy engaging in interpersonal interactions with others whilst performing their work and are thus more likely to engage in helping behaviours, fill in for sick colleagues and take on extra workload for those that they have previously established relationships with through relational crafting. Finally, individuals who score high on cognitive crafting are expected to perform better in their IRB and OCB-I than those who score low. Through cognitive crafting, individuals redefine the purpose of their work and subsequently derive more meaning from it (Tims, Bakker, \& Derks, 2016; Wrzesniewski \& Dutton, 2001). This increased meaningfulness sparks a fire within individuals to persist and give their all at work, ultimately having a positive impact on their task performance (IRB). Furthermore, individuals who craft their work cognitively are also more likely to help 
those around them and speak good things about their organisation as they find that their job has a meaningful contribution in the greater scheme of things. Thus, the following hypothesis is formulated:

H1: There is a positive relationship between:

H1a: task crafting and IRB.

H1b: relational crafting and OCB-I.

H1c: cognitive crafting and IRB.

H1d: cognitive crafting and OCB-I.

Extensive research has established the outcomes of engaging in job crafting behaviour with improved job performance as one of the most salient features. There, however, remains a paucity of empirical investigations that explore the individual antecedents to job crafting behaviour. As stated by Berdicchia, Nicolli and Masino (2016), the role that individual differences play in promoting or demoting job crafting behaviours is still relatively unexplored. Previous researches have mainly focused on contextual factors (i.e. work discretion, supervision and task interdependence) as predictors of job crafting behaviour (see Ghitulescu, 2006; Leana et al., 2009), with only a few attempts being made to explore the individual antecedents. For example, Tims et al. (2015) found that individuals' intentions to craft their jobs and their levels of work engagement were both positive predictors of actual job crafting behaviour. Other theoretical arguments concerning the antecedents of job crafting have also been made. Demerouti and Bakker (2014), for instance, proposed that individuals engage in job crafting behaviour to attain work goals, to create better working conditions for themselves and to improve their overall person-environment fit, whilst Wrzesniewski and Dutton (2001) stated that employees craft to fulfil their basic psychological needs (i.e. need for control, need for a positive self-image and need for connection with others).

This study proposes that personality, as measured by the FFM, predicts individual's job crafting propensities, which, in turn, affect how they perform. That is, job crafting acts as a mediator between the 'Big Five' and job performance. Both job crafting (Wrzesniewski \& Dutton, 2001) and job performance (Campbell, 1990) are regarded as actions, and because personality affects the actions of individuals (McCrae \& Costa, 1992), it makes sense to expect personality to influence the way one crafts and ultimately performs on the job. The rationale for selecting the 'Big Five' as a predictor of job crafting is threefold: firstly, some features of the 'Big Five' personality traits (e.g. agreeableness) are similar to those of the job crafting dimensions (e.g. relational crafting); secondly, the FFM is a robust personality taxonomy whose structure is universal and generalisable across languages, cultures and various other demographic variables (Goldberg, 1990; McCrae \& Costa, 1997; Norman, 1967; Tupes \& Christal, 1961); thirdly, there is a shortage of research exploring the predictive validity of personality, in particular the FFM, on job crafting.

Interestingly, a study by Bakker, Tims and Derks (2012) found that individuals with a proactive personality were more likely to craft their work than their more passive counterparts. Most recently, and contrary to some of their expectations, Bell and Njoli (2016) found openness to experience, neuroticism, conscientiousness and agreeableness to be significant predictors of job crafting behaviour.

This study anticipates that some of the 'Big Five' personality traits are more strongly related to specific job crafting behaviours than to others. It is expected that the social traits extraversion and agreeableness will relate most strongly to relational crafting, as individuals high on these traits have the tendency to be talkative, outgoing, affectionate, kind and warm (John \& Srivastava, 1999), which are the necessary features to form and sustain healthy relationships. According to Ozer and Benet-Martínez (2006), the strength and quality of relationships are influenced by the dispositions of individuals, and therefore, it is plausible to argue that the likelihood of individuals engaging in social interactions with their fellow co-workers is influenced by their standing on the traits extraversion and agreeableness. Thus, the following hypothesis is formulated:

H2:

H2a: Extraversion and agreeableness are positively related to relational crafting.

H2b: Relational crafting mediates the relationship between extraversion and OCB-I.

H2c: Relational crafting mediates the relationship between agreeableness and OCB-I.

With regard to conscientiousness, it is expected that highly conscientious individuals will craft their task boundaries more so than their relational or cognitive boundaries, which, in turn, will affect their IRB.

Research has indeed found conscientiousness to be the strongest predictor of task performance (Barrick \& Mount, 1991). We argue that individuals who score high on conscientiousness will perform better in their in-role activities by means of task crafting, as they have the tendency to organise and structure their work to ensure that it aligns with their personal strengths and preferences. Thus, the following hypothesis is made:

H3:

H3a: There is a positive relationship between conscientiousness and task crafting.

H3b: Task crafting mediates the relationship between conscientiousness and IRB.

Because job crafting offers somewhat of a new approach to job redesign that requires employees to take their own initiative in shaping their job characteristics, it is believed that an individual would need to possess some degree of openness to experience and to engage in this novel behaviour. Individuals who are low on openness to experience are probably less likely to try new things such as job crafting, whilst those who are curious, imaginative and willing to try new things (i.e. high on openness) are probably 
more likely to step out of their comfort zone and engage in job crafting behaviour. Furthermore, highly open individuals may use their imaginations to find new and creative ways of improving the design of their jobs and their subsequent IRB. Thus, the following hypothesis is made:

\section{H4:}

H4a: There is a positive relationship between openness to experience and task crafting.

H4b: Task crafting mediates the relationship between openness to experience and IRB.

Finally, it is expected that individuals who score high on neuroticism are less likely to engage in relational crafting behaviour. Neurotic individuals have the tendency to display fluctuating moods, to be emotionally unstable and to be quite tense and touchy (John \& Srivastava, 1999), all of which may affect the ability of the individual to establish and maintain healthy relationships at work, which, in turn, may affect their performance and, in particular, their OCB-I. Thus, the following hypothesis is formulated.

H5:

H5a: There is a negative relationship between neuroticism and relational crafting.

H5b: Relational crafting mediates the negative relationship between neuroticism and OCB-I.

\section{Method}

\section{Participants}

To participate in this research, individuals were required to be South African working individuals, have a minimum Grade 10 education level, be proficient in English and be willing to participate. The total sample consisted of 580 individuals, of which 263 (46\%) were men and 315 (54\%) were women. The average age and organisational tenure were 35 years (standard deviation $[S D]=11.24$ ) and 7 years $(\mathrm{SD}=8.05)$, respectively.

With regard to marital status, the majority of the sample identified themselves as single $(45 \%)$ or engaged in a relationship (36\%). The majority $(87 \%)$ of the sample were full-time working individuals, whilst the remaining were part-time (6\%) or self-employed (4\%). The sample represented various industries including legal, banking, insurance, education, healthcare, retail and information technology.

\section{Measures}

The Basic Traits Inventory (BTI) (Taylor \& De Bruin, 2006) was used to measure the 'Big Five' personality traits of extraversion (e.g. 'I find it easy to talk to people I have just met'), agreeableness (e.g. 'I am a friendly person'), conscientiousness (e.g. 'I double-check my work for mistakes'), neuroticism (e.g. 'I find it difficult to control my feelings') and openness to experience (e.g. 'I like to experience new things'). Each trait measure comprises 12 items that are rated on a five-point Likert scale with possible responses ranging from 1 (strongly disagree) to 5 (strongly agree).
The BTI, developed specifically for the South African context, has shown to be cross-culturally valid and to possess sound psychometric properties (Taylor \& De Bruin, 2006). The current study found reliability coefficients of 0.82 for openness, 0.90 for conscientiousness, 0.79 for extraversion, 0.83 for agreeableness and 0.85 for neuroticism.

The Job Crafting Questionnaire (JCQ) (Slemp \& VellaBrodrick, 2013) was used to measure task (e.g. 'I introduce new approaches to improve my work'), relational (e.g. 'I organise or attend work-related social functions') and cognitive crafting (e.g. 'I think about how my job gives my life purpose'). The JCQ contains 15 items, with each dimension being captured by five items. Respondents are asked to rate the extent to which they engage in the various forms of job crafting on a frequency scale ranging from 1 (hardly ever) to 6 (very often). Reliability analyses have shown the JCQ to be a reliable measure of job crafting behaviour (Slemp \& Vella-Brodrick, 2013). The current study found reliability coefficients of 0.74 for task crafting, 0.71 for relational crafting and 0.82 for cognitive crafting.

Job performance was measured with Williams and Anderson's (1991) Job Performance Scale. IRB (e.g. 'I adequately complete assigned duties') and OCB-I (e.g. 'I help others who have been absent') were each measured with seven items and rated on a five-point Likert scale ranging from 1 (strongly disagree) to 5 (strongly agree). Previous researches have demonstrated good psychometric properties for the IRB and OCB-I subscales (Tims et al., 2014). The current study found reliability coefficients of 0.78 for IRB and 0.77 for OCB-I.

\section{Research procedure}

As part of their course work in a research methodology module, undergraduate students were instructed to administer the questionnaires to South African working individuals who met the research criteria.

Advantages of student-recruited samples include heterogeneity, student learning, cost reduction and elaborate research designs (cf. Demerouti \& Rispens, 2014). In line with the suggestions made by Demerouti and Rispens (2014) to guard the quality of student-recruited data, we ensured that all instructions given to students were clear, that the process of data collection was standardised across all students and that each student was given a feasible amount of data to collect (i.e. five participants per student) - all of which are said to minimise the pressure on students and eliminate any form of counterproductive behaviour (i.e. cheating).

The sealed envelopes contained a biographical questionnaire and the three instruments used to capture the variables under study. A cover letter accompanied each questionnaire explaining the purpose as well as the confidential and anonymous nature of the study. Participants were also provided with the contact details of the researcher in 
the case that they wanted any uncertainties to be attended to. Once the participants completed the surveys, they were requested to place and seal them in the envelopes, which were subsequently stored in a secure location.

\section{Statistical analysis}

All analyses were carried out in the statistical program $R$ (R Core Team, 2016) using the psych (Revelle, 2016), lavaan (Rosseel, 2012) and sem (Fox, Nie \& Byrnes, 2012) packages. $R$ enables researchers to employ various statistical techniques such as structural equation modelling (SEM) (Culpepper \& Aguinis, 2011).

To summarise the basic features of the data, descriptive statistics were inspected, including the mean, standard deviation, measures of central tendency (i.e. skewness and kurtosis) and reliability (Cronbach's alpha) of the scales. In addition, Pearson's product-moment correlation was used to assess the strength of the linear relationships between the variables.

To investigate the indirect relationships between personality and performance through job crafting behaviour, SEM was used. Two steps were followed when performing the SEM analysis, with the first step being the measurement component (essentially the CFA) and the second step being the structural component (Schreiber, Stage, King, Nora, \& Barlow, 2006). Goodness-of-fit (GOF) statistics were inspected for evaluating the model fit, which included the incremental fit indices (i.e. $\chi^{2}$, Tucker Lewis Index [TLI], Confirmatory Fit Index [CFI]) and the absolute fit indices (i.e. Root Mean Square Error of Approximation [RMSEA] and Standardised Root Mean Square Residual [SRMR]). This study used conventional cut-off values for assessing the overall model fit (i.e. CFI and TLI $\leq 0.90$, RMSEA and SRMR $\leq$ 0.08; Browne \& Cudeck, 1993; Marsh, Hau, \& Wen, 2004). Weighted least squares mean and variance adjusted (WLSMV) was used as the estimation method, which, according to Schumacker and Lomax(2010), does not depend on the normality assumption. Brown (2006) further argues that WLSMV as a robust estimator does not assume normally distributed variables, and it provides the best option for modelling ordered data. To assess the reliability of the SEM models, McDonald's (1999) coefficient omega hierarchical $\left(\omega \_h\right)$ was used. Omega is a more sensible index of internal consistency that is less at risk to overestimate or underestimate reliability (cf. Dunn, Baguley, \& Brunsen, 2013).

\section{Ethical consideration}

The research was approved by the research and ethics committee of the Department of Industrial Psychology and People Management at the University of Johannesburg.

\section{Results}

\section{Descriptive statistics and correlations}

The descriptive statistics and Pearson's product-moment correlations are presented in Table 1.

Looking at the job crafting-job performance relationship, significant positive relationships were found between task crafting and IRB, relational crafting and OCB-I, cognitive crafting and IRB, and cognitive crafting and OCB-I, providing support for hypothesis $1 \mathrm{a}$ to $1 \mathrm{~d}$. Furthermore, extraversion and relational crafting, agreeableness and relational crafting, conscientiousness and task crafting, and openness to experience and task crafting had significant positive relationships, providing support for hypotheses $2 \mathrm{a}, 3 \mathrm{a}$ and $4 a$, respectively. Hypothesis $5 a$, which stated that there would be a negative relationship between neuroticism and relational crafting, was also supported.

\section{Structural equation modelling}

\section{Extraversion, relational crafting and organisational citizenship behaviour-I}

To investigate the indirect relationship between extraversion and OCB-I through relational crafting (hypothesis 2b), the hypothesised measurement model (ModelEx1) was specified, consisting of three latent variables: extraversion (12 items), relational crafting (five items) and OCB-I (seven items). The standardised loadings ranged from 0.22 to 0.79 . One extraversion item ('I like to be the centre of attention') had an undesirably low factor loading of $0.22\left(R^{2}=0.05\right)$ and was thus removed. ModelEx1 was compared to an alternative model (ModelEx1b) where all items were made to load onto a single latent variable, and unsurprisingly, the fit of the

TABLE 1: Descriptive statistics, means, standard deviations and correlations $(N=580)$.

\begin{tabular}{|c|c|c|c|c|c|c|c|c|c|c|c|c|c|c|}
\hline Measure & $M$ & SD & Skew & Kurt & 1 & 2 & 3 & 4 & 5 & 6 & 7 & 8 & 9 & 10 \\
\hline 1. Task crafting & 4.05 & 1.05 & -0.39 & -0.07 & - & - & - & - & - & - & - & - & - & - \\
\hline 2. Relational crafting & 4.17 & 1.02 & -0.28 & -0.33 & $0.43 * *$ & - & - & - & - & - & - & - & - & - \\
\hline 3. Cognitive crafting & 4.64 & 1.05 & -0.77 & 0.28 & $0.43 * *$ & $0.37 * *$ & - & - & - & - & - & - & - & - \\
\hline 4. In-role behaviour & 4.28 & 0.55 & -0.79 & 0.88 & $0.30 * *$ & $0.23 * *$ & $0.34 * *$ & - & - & - & - & - & - & - \\
\hline 5. Organisational citizenship behaviour & 3.64 & 0.68 & -0.45 & 0.46 & $0.33 * *$ & $0.33 * *$ & $0.22 * *$ & $0.29 * *$ & - & - & - & - & - & - \\
\hline 6. Openness & 3.79 & 0.58 & -0.33 & 0.33 & $0.14 * *$ & $0.12 * *$ & $0.09 *$ & 0.09 & $0.16 * *$ & - & - & - & - & - \\
\hline 7. Conscientiousness & 3.98 & 0.68 & -0.71 & 0.66 & $0.12 * *$ & $0.16 * *$ & $0.14 * *$ & $0.16 * *$ & $0.22 * *$ & $0.48 * *$ & - & - & - & - \\
\hline 8. Extraversion & 3.63 & 0.59 & -0.50 & 0.11 & $0.16 * *$ & $0.25 * *$ & $0.18 * *$ & $0.13 * *$ & $0.21 * *$ & $0.41 * *$ & $0.38 * *$ & - & - & - \\
\hline 9. Agreeableness & 3.95 & 0.57 & -0.63 & 1.04 & 0.08 & $0.18 * *$ & $0.12 * *$ & $0.10 *$ & $0.23 * *$ & $0.54 * *$ & $0.58 * *$ & $0.33 * *$ & - & - \\
\hline 10. Neuroticism & 2.39 & 0.72 & 0.31 & -0.36 & $-0.10 *$ & $-0.18 * *$ & -0.06 & $-0.13^{* *}$ & $-0.12 * *$ & $-0.29 * *$ & $-0.30 * *$ & $-0.21 * *$ & $-0.31 * *$ & - \\
\hline
\end{tabular}

$\mathrm{M}$, mean; $\mathrm{SD}$, standard deviation.

$*, p<0.05 ; * * p,<0.01$. 
alternative model was substantially worse $\chi_{(252)}^{2}=2734.81$; $\mathrm{CFI}=0.56$; TLI $=0.52 ;$ RMSEA $=0.14$ [90\% CI: 0.135, 0.144]; SRMR $=0.13$ ). In the second step, the structural paths between the latent variables were modelled with both the direct and indirect relationships included (ModelEx2), where extraversion served as the independent variable, OCB-I as the dependent variable and relational crafting as the mediator $\left(\chi_{(227)}^{2}=826.66 ; \mathrm{CFI}=0.89 ; \mathrm{TLI}=0.88 ; \mathrm{RMSEA}=0.07[90 \% \mathrm{CI}:\right.$ $0.067,0.077]$; SRMR $=0.067)$. The implied theoretical model was not as strong as desired and so an investigation of the modification indices was performed.

The results showed that if the residuals of two extraversion items ('People see me as an energetic person' and 'I am usually active') were allowed to correlate, there would be an approximate 56.51 decrease in the chi-square value. Furthermore, if the residuals of two additional extraversion items ('I like to meet people' and 'I it easy to talk to people I have just met') were allowed to correlate, there would be an approximate 125.69 decrease in chi-square value. Lastly, if the residuals of two job crafting items ('I organise or attend workrelated social functions' and 'I choose to mentor new employees') were allowed to cross-load onto OCB-I, there would be a decrease of 65.05 and 63.56 in the chi-square value, respectively. It was evident that these items shared some common unexplained variance and thus the modifications were applied.

The structural model (ModelEx2a) was then run with the modifications included and it produced a good fit $\left(\chi^{2}{ }_{(223)}=\right.$ 602.34; CFI $=0.93$; TLI $=0.92 ;$ RMSEA $=0.06$ [90\% CI: 0.052, 0.063 ]; SRMR $=0.06$ ). ModelEx2a showed that there was an indirect positive relationship between extraversion and OCB-I through relational crafting $(\beta=0.14, p<0.001)$, providing support for Hypothesis 2b. McDonald's (1999) omega hierarchical was 0.87 , which is indicative of good model reliability. Figure 2 depicts the final hypothesised structural model with the standardised path estimates.

\section{Agreeableness, relational crafting and organisational citizenship behaviour-I}

To investigate the indirect relationship between agreeableness and OCB-I through relational crafting (Hypothesis 2c), the hypothesised measurement model (ModelA1) was specified with three latent constructs: agreeableness (12 items), relational crafting (five items) and OCB-I (seven items).

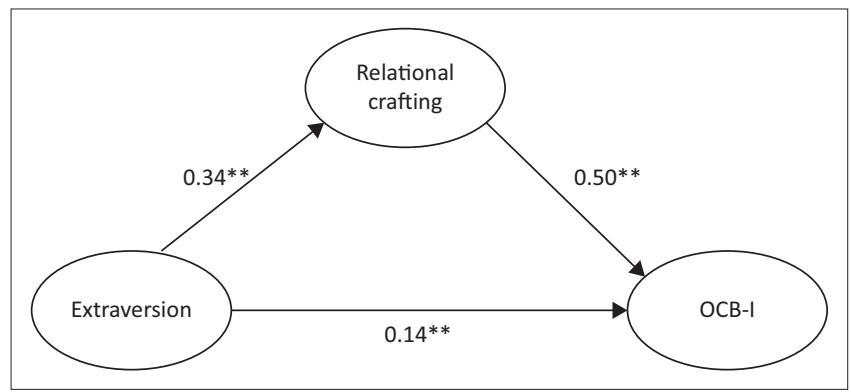

$* *, p<0.01$.

FIGURE 2: Path diagram between extraversion, relational crafting and organisational citizenship behaviour-I.
The standardised loadings were all significant and ranged from 0.39 to 0.77 on their respective construct. ModelA1 was compared to an alternative model (ModelA1b) where all items were set to load onto a single latent construct.

As anticipated, the alternative one-factor model showed a worse fit $\chi_{(252)}^{2}=3156.78 ; \mathrm{CFI}=0.53$; TLI $=0.48$; RMSEA $=0.15$ [90\% CI: 0.145, 0.152]; SRMR $=0.14$ ); therefore, the original hypothesised measurement model was subjected to further analysis.

In the second step, the direct and indirect structural paths were specified between the independent (i.e. agreeableness), dependent (OCB-I) and mediator (relational crafting) variables. The hypothesised structural model (ModelA2) produced the following fit: $\chi_{(249)}^{2}=877.38 ; \mathrm{CFI}=0.90$; $\mathrm{TLI}=0.89 ;$ RMSEA $=0.07$ [90\% CI: 0.065, 0.075]; SRMR $=0.07$. Not completely satisfied with the overall fit of the structural model, a modification search was conducted. Previous model specification searches in earlier analyses highlighted that the residuals of two job crafting items belonging to relational crafting wanted to load onto OCB-I. As the same two variables (i.e. relational crafting and OCB-I) were used in this analysis, it made practical sense to modify these two model parameters accordingly. Inspection of the modification indices corroborated previous findings, showing that if we allowed the residuals of the two relational crafting items to cross-load onto OCB-I, there would be a 63.25 and 71.83 approximate decrease in chi-square, respectively.

Additionally, it was found that if we allowed the residuals of two items ('I give clothes or food to needy people' and 'I like to donate things to a good cause') from the agreeableness factor to correlate, there would be a 149.28 approximate decrease in chi-square. Having substantive reasons to do so, the suggested modifications were applied, and the new structural model was run (ModelA2a), producing a better fitting model $\left(\chi_{(246)}^{2}=663.05 ; \mathrm{CFI}=0.93 ; \mathrm{TLI}=0.92 ; \mathrm{RMSEA}=\right.$ 0.06 [90\% CI: 0.052, 0.063]; SRMR = 0.06). Investigation of the path estimates showed that there was a positive indirect relationship between agreeableness and OCB-I through relational crafting behaviour $(\beta=0.10, p<0.001)$, providing support for Hypothesis 4c. The reliability $\left(\omega \_h\right)$ of the hypothesised structural model was 0.88 . Figure 3 provides the standardised estimates for the final structural model.

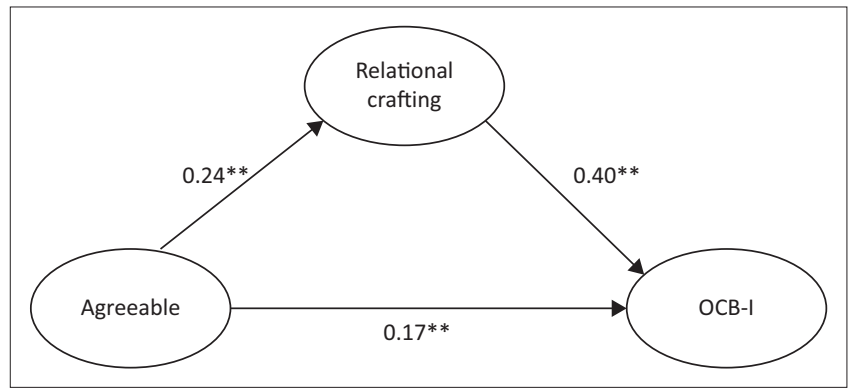

$* *, p<0.01$.

FIGURE 3: Path diagram between agreeableness, relational crafting and organisational citizenship behaviour-I. 


\section{Conscientiousness, task crafting and in-role behaviour}

To investigate the indirect relationship between conscientiousness and IRB through task crafting behaviour (Hypothesis 3b), the hypothesised measurement model (ModelC1) was specified with three latent variables, conscientiousness (12 items), task crafting (five items) and IRB (seven items). The standardised loadings ranged from 0.44 to 0.91 across the three latent variables. ModelC1 was compared to an alternative one-factor model (ModelC1a), which unsurprisingly showed a poor fit $\left(\chi_{(252)}^{2}=4290.34\right.$ $\mathrm{CFI}=0.61 ; \mathrm{TLI}=0.58 ; \mathrm{RMSEA}=0.18$ [90\% CI: 0.173, 0.182] SRMR $=0.19$ ).

In the second step, the hypothesised structural paths between the latent variables were specified (ModelC2). ModelC2 consisted of three latent variables, namely, agreeableness (independent variable), task crafting (mediator) and IRB (dependent variable). ModelC2 yielded a good fit $\left(\chi_{(249)}^{2}=757.48\right.$; $\mathrm{CFI}=0.95$; TLI $=0.95$; RMSEA $=0.06$ (90\% CI: 0.058, 0.069); SRMR = 0.06). The path estimates showed that there was an indirect relationship between conscientiousness and IRB through task crafting behaviour $(\beta=0.06, p<0.01)$, providing support for Hypothesis 3b. McDonald's (1999) omega hierarchical showed a good reliability for the hypothesised structural model (0.92). The standardised path estimates of the direct and indirect relationships are shown in Figure 4.

\section{Openness to experience, task crafting and in-role behaviour}

To investigate the indirect relationship between openness and IRB through task crafting (Hypothesis 4b), the hypothesised measurement model (ModelO1) was specified, which consisted of three latent variables: openness to experience (12 items), task crafting (five items) and IRB

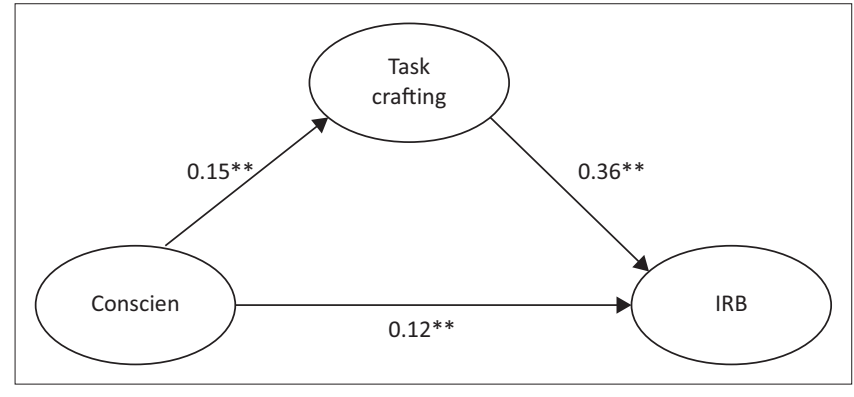

$* *, p<0.01$.

FIGURE 4: Path diagram between conscientiousness, task crafting and in-role behaviour.

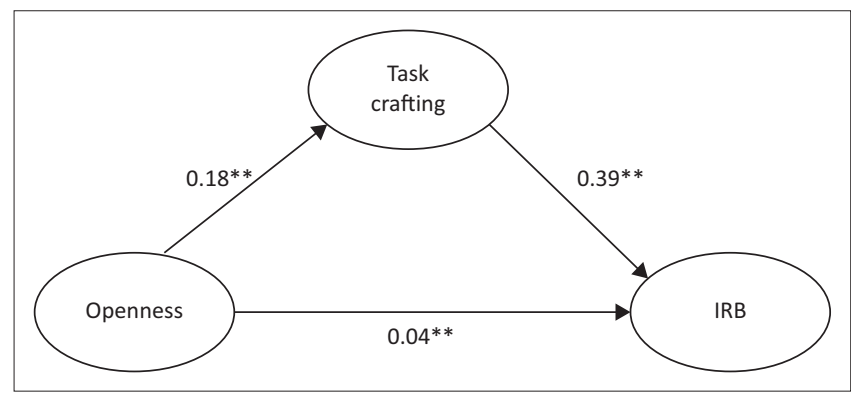

$* *, p<0.01$.

FIGURE 5: Path diagram between openness, task crafting and in-role behaviour. (seven items). The standardised factor loadings ranged from 0.45 to 0.93 across all the items. ModelO1 was compared to an alternative model (ModelO1b) whereby all the items were set to load onto a single latent variable, and unsurprisingly the alternative model showed a worse fit $\left(\chi_{(189)}^{2}=.3027 .74 ; \mathrm{CFI}=0.61 ; \mathrm{TLI}=0.56 ; \mathrm{RMSEA}=0.17[90 \%\right.$ CI: $0.168,0.179]$; SRMR $=0.19$ ).

In the second step, the hypothesised structural model (ModelO2) was constructed with both the direct and indirect paths specified between the three latent variables: openness (independent variable), task crafting (mediator) and IRB (dependent variable). ModelO2 produced a good fit: $\chi^{2}{ }_{(249)}=$ 642.54; CFI $=0.95 ;$ TLI $=0.94 ;$ RMSEA $=0.06$ (90\% CI: 0.051 , $0.062) ; \mathrm{SRMR}=0.06$. Upon further inspection, task crafting was found to mediate the relationship between openness and $\operatorname{IRB}(\beta=0.07, p<0.001)$, providing support for Hypothesis $4 \mathrm{~b}$. McDonald's coefficient omega for the overall model was 0.88 , which is suggestive of good model reliability. Figure 5 depicts the standardised path estimates for ModelO2. The direct relationship between openness and IRB was not statistically significant $(p=0.478)$ and hence there is a dashed path between the constructs.

\section{Neuroticism, relational crafting and organisational citizenship behaviour-I}

To investigate the indirect relationship between neuroticism and OCB-I through relational crafting (Hypothesis 5b), the hypothesised measurement model (ModelN1) was first specified. Consisting of three latent variables, namely, neuroticism (12 items), relational crafting (five items) and OCB-I (seven items), the measurement model converged after 48 iterations and produced the following fit: $\chi_{(249)}^{2}=0.892 .74$; $\mathrm{CFI}=0.91$; TLI $=0.90 ; \mathrm{RMSEA}=0.07$ (90\% CI: 0.066, 0.076); $\mathrm{SRMR}=0.07$. The original measurement model was compared to a new model (ModelN1a) that consisted of modifications to the two latent factors - relational crafting and OCB-I - that were suggested by previous modification indices in earlier analyses. One item from neuroticism was also removed as it produced a low standardised factor loading of $0.36\left(R^{2}=0.13\right)$ in comparison to the other items. The new measurement model (ModelN1a) yielded an improved fit $\chi_{(247)}^{2}=0.817 .39$; $\mathrm{CFI}=0.93$; TLI $=0.92 ; \mathrm{RMSEA}=0.06$ [90\% CI: 0.058, 0.069]; SRMR $=0.06)$ and was then subjected to the structural component of the analysis.

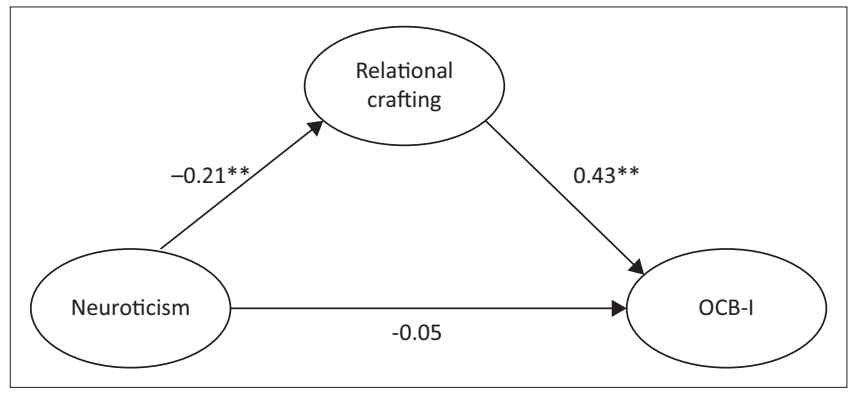

$* *, p<0.01$.

FIGURE 6: Path diagram between neuroticism, relational crafting and organisational citizenship behaviour-I. 
TABLE 2: Test of unique indirect relations.

\begin{tabular}{|c|c|c|c|c|c|c|c|c|}
\hline \multirow[t]{2}{*}{ Predictor } & \multirow[t]{2}{*}{ Mediator } & \multirow[t]{2}{*}{ Criterion } & \multirow[t]{2}{*}{$\beta$} & \multirow[t]{2}{*}{ Estimate } & \multirow[t]{2}{*}{ SE } & \multirow[t]{2}{*}{$P$} & \multicolumn{2}{|c|}{$95 \% \mathrm{Cl}$ of the Indirect Effects } \\
\hline & & & & & & & Lower & Upper \\
\hline Extraversion & Relational crafting & OCB-I & 0.14 & 0.18 & 0.04 & $0.000 * *$ & 0.10 & 0.26 \\
\hline Agreeableness & Relational crafting & OCB-I & 0.10 & 0.14 & 0.03 & $0.000 * *$ & 0.07 & 0.20 \\
\hline Conscientiousness & Task crafting & IRB & 0.06 & 0.07 & 0.03 & $0.005 * *$ & 0.02 & 0.12 \\
\hline Openness & Task crafting & IRB & 0.07 & 0.09 & 0.03 & $0.001 * *$ & 0.04 & 0.16 \\
\hline Neuroticism & Relational crafting & OCB-I & -0.09 & -0.11 & 0.03 & $0.000 * *$ & -0.17 & -0.05 \\
\hline
\end{tabular}

Note: $\mathrm{Cl}$ Upper and $\mathrm{Cl}$ Lower $=95 \%$ confidence intervals of the indirect effects.

IRB, in-role behaviour; $\mathrm{Cl}$, confidence interval; $\mathrm{SE}$, standard error; OCB-I, organisational citizenship behaviour-I.

$* *, p<0.01$.

For the structural model (ModelN2), neuroticism served as the independent variable, relational crafting as the mediator and OCB-I as the dependent variable. The fit of the structural model was as follows: $\chi_{(247)}^{2}=0.817 .39 ; \mathrm{CFI}=0.93$; TLI $=0.92$; RMSEA $=0.06$ [90\% CI: 0.058, 0.069]; SRMR $=0.06$. ModelN2 showed that there was an indirect negative relationship between neuroticism and OCB-I through relational crafting $(\beta=-0.09, p<0.001)$, providing support for Hypothesis $5 b$. McDonald's coefficient omega for the overall model was 0.84 , which is suggestive of good model reliability. Figure 6 depicts the standardised path estimates for the structural model. Note that the direct relationship between neuroticism and OCB-I was not statistically significant $(p=0.25)$ and hence there is a dashed path between the constructs. Table 2 summarises the test of the unique indirect relationships between the study variables.

\section{Discussion}

This study aimed to investigate the indirect relationship between personality and performance through job crafting behaviour. It was generally hypothesised that the 'Big Five' personality traits would indirectly affect job performance (i.e. in-role behaviour and organisational citizenship behaviour) through job crafting. In summary, this study revealed that an individual's personality indirectly affects his or her job performance through job crafting behavioural processes, with the effect sizes falling within the moderate range. In the following, the most important findings and contributions of this study are discussed.

\section{Five-Factor Model $\rightarrow$ job crafting $\rightarrow$ job performance}

Whilst research has explored the outcomes of job crafting behaviour, there is proportionately much less research concerning the individual antecedents that promote or encourage job crafting (Berdicchia et al., 2016). This study embarked on a quest to investigate whether personality, as measured by the 'Big Five', predicts individuals' job crafting behaviour and their subsequent job performance. The findings largely supported the research hypotheses. That is, all the 'Big Five' personality traits were found to predict job crafting behaviour and, in turn, job performance. These findings lend support to the scant amount of previous researches that have found individual characteristics (i.e. personality) to predict job crafting behaviour (Bakker et al., 2012; Bell \& Njoli, 2016) and also provide empirical support to theoretical arguments made by Oldham and Fried (2016), who stated that employees respond differently to their job characteristics as a function of their personalities. Furthermore, consistent with previous literature (e.g. Demerouti, Bakker, \& Halbesleben, 2015; Leana et al., 2009), this study also found that employees can indeed use job crafting to increase their job performance.

Employees high on extraversion and agreeableness engage in relational crafting behaviour, which results in an increase in their OCB-I. This finding suggests that employees who are characteristically social (e.g. talkative, warm, kind and friendly) modify their job characteristics by increasing the amount of social interaction with others at work, which leads to them going beyond their role requirements and engaging in helping behaviours (i.e. OCB-I) towards other individuals. Indeed, researchers have found that extraversion and agreeableness are positively related to the interpersonal component of contextual performance (i.e. OCB-I; Organ \& Ryan, 1995; Van Scotter \& Motowidlo, 1996) and therefore this result was expected. This study not only supports these previous findings but also extends them by showing that these two traits (i.e. extraversion and agreeableness) are also indirectly related to OCB-I through relational crafting.

Furthermore, owing to the fact that the sample represented a diverse range of occupations, the results of this study show that extraversion and agreeableness are not only important for job performance in occupations that require high social interaction (e.g. Barrick \& Mount, 1991) but also across general work.

With respect to task crafting, this study supported the proposition that employees who are conscientious and open to experience engage in task crafting behaviour, which, in turn, results in increased IRB (i.e. task performance). This finding suggests that individuals who are well organised, dependent, responsible and self-disciplined (i.e.conscientious), as well as those who are open-minded, creative and willing to try new things (i.e. open to experience), are more likely to shape the physical aspects of their jobs to experience a better fit between their own personal characteristics and the characteristics of the job, which, in turn, yields positive returns for their IRB. Firstly, the positive association between job crafting and IRB (i.e. task performance) corroborates previous research finding on job crafting (Demerouti, Bakker, \& Gevers, 2015). Secondly, it supports the idea that employees can use job crafting (i.e. task crafting) as a strategy to positively influence their work environment and work experiences that may contribute to more favourable work 
outcomes, such as increased job performance (Oldham \& Hackman, 2010; Tims, Bakker, \& Derks, 2016).

The last 'Big Five' trait that was explored in relation to job crafting and job performance was neuroticism. The results supported the hypothesis that there is an indirect negative relationship between neuroticism and OCB-I through relational crafting behaviour (Hypothesis 5b). Perhaps, because of their general negative affect and/or their inability to control their emotions (McCrae \& Costa, 1997), highly neurotic individuals are less likely to be successful in establishing relationships with others at work through, for instance, relational crafting, which, in turn, leads to them being less likely to go beyond their task requirements by helping others or engaging in OCB towards other individuals. Although limited research exists regarding the relationship between neuroticism and relational crafting (e.g. Bell \& Njoli, 2016), research has found that individuals who score high on neuroticism report less satisfaction with their relationships at work (Scollon \& Diener, 2006), providing a good reasoning for why the current study observed a negative relationship between neuroticism and relational crafting. Lastly, the results further support previous researches that have found a negative relationship between neuroticism and job performance (Rothman \& Coetzer, 2003; Tett, Jackson, \& Rothstein, 1991).

\section{Practical implications and contributions of the study}

Job crafting has important implications for an individual's job performance (Gordon et al., 2015; Tims et al., 2015), making it imperative for organisations to understand the factors that predict such behaviour. This study showed that an individual's personality influences the types of crafting behaviours that he or she engages in at work, which, in turn, have implications for his or her job performance. Based on the findings, we suggest that organisations encourage and promote job crafting practices in the workplace by allowing employees to use and express their personality traits to improve employee job performance. This study necessitates the need for organisations to take special consideration of an individual's personality (i.e. personal disposition) when making important selection and placement decisions. Acknowledging the personality of employees further helps us understand how employees respond to their tasks and relationships at work.

This study contributes to the existing literature in a number of ways. The first contribution is that personality can indeed affect job performance indirectly, supporting previous claims that personality is an indirect determinant (Johnson \& Schneider, 2013). According to Beaty, Cleveland and Murphy (2001), research reporting the direct personality-performance relationship is often small in magnitude, and it may just be that there are underlying behavioural mechanisms (i.e. mediators) that can help better explain the association between these two constructs. As shown in the current study, job crafting can help explain the indirect relationship between personality and job performance. With respect to job crafting, little research has been conducted exploring its individual antecedents (Berdicchia et al., 2016), and they mainly focus on contextual factors that predict job crafting (see Ghitulescu, 2006; Leana et al., 2009).

This study therefore allows us to understand which personality traits are associated with different job crafting behaviours and performance. The study showed that an individual's personality (i.e. Big Five) undeniably influences the type of job crafting behaviour employees participate in, thereby contributing to the small amount of research that has explored personality as an antecedent to job crafting behaviour (Bakker et al., 2012; Bell \& Njoli, 2016). In doing so, this study answers calls made to investigate the individual antecedents that promote job crafting behaviour (Oldham \& Fried, 2016; Vogt et al., 2016; Wrzesniewski \& Dutton, 2001).

\section{Limitations and recommendations for future research}

There are a few limitations of the current study. The first one is the self-report nature of the questionnaires, which are known to introduce common method variance (CMV).

Common method variance is a problem particularly relevant to behavioural research that has the ability to compromise the validity of conclusions derived from a study (cf. Podsakoff, MacKenzie, \& Lee, 2003). In the current study, the chances of CMV creeping into this study were reduced as different scale response formats were used across the measurement instruments (see Podsakoff et al., 2003). Future researchers could consider using alternative rating sources (i.e. supervisor and colleague) when measuring behaviours at work. The design of this study was cross-sectional in nature (which in itself is a limitation as causality cannot be assigned) with scores being taken at a single point in time. It could be that personality traits present themselves over the long run, and therefore it is recommended that future researchers should consider the issue of methodological measurement separation (see Podsakoff et al., 2003). In particular, researchers may want to create temporal separation by introducing time lags in between the measurement of the predictor (i.e. personality) and criterion variable, respectively, so that participants avoid making links or associations between the respective constructs. This, however, may not be possible when time is limited or when data are collected over shorter time periods (i.e. week- or day-level studies).

The next limitation of this study regards the level at which the statistical analysis was conducted. The 'Big Five' traits were analysed at the general or trait level. The analysis did not consider the facets within each factor or trait. It may be worthwhile for future researchers to look at the deep facetcomposition level to gain a better understanding of personality as a predictor of job crafting and self-undermining behaviour and their subsequent effects on job performance. 
As stated by Saucier and Goldberg (2003, p. 14), 'a better way to understand each factor might be to characterize its crucial subcomponents'. The present study also did not consider any potential moderating variables that could have strengthened or weakened the personality-performance relationship. Therefore, future researchers should consider moderators that may strengthen or weaken the magnitude of the relationships or the variances accounted for in each respective personality-performance relationship. As previous research has shown, certain personality traits (e.g. extraversion and agreeableness) are only important in certain contexts, such as sales (e.g. Barrick \& Mount, 1991). Barrick and Mount (1993) demonstrated that personality predicted managerial performance when autonomy (moderator) was high. Future researchers may therefore want to consider the type of work, job level or industry that an individual works in as potential moderating variables, which may strengthen or weaken the personality-performance relationship.

A final recommendation that future SEM researchers should take into consideration is the utility of modification indices in improving model fit. As was demonstrated in the current research, when the fit of the implied theoretical model is not as strong as desired, model modifications may prove to be particularly useful. Future researchers wishing to investigate the relationships between the variables used in this study should consider undertaking a thorough investigation of model parameters (including the residual matrix) to determine whether specification errors exist that may be causing model misfit. However, it is imperative to ensure that model modifications are guided by practical significance and substantive meaning (Schumacker \& Lomax, 2010).

\section{Conclusion}

This study showed that an individual's personality, as measured by the 'Big Five', indirectly affects his or her job performance through two specific behavioural processes: job crafting and self-undermining. Employees express their personality traits by engaging in job crafting behaviour, which, in turn, has implications for their in-role behaviour and organisational citizenship behaviour.

\section{Acknowledgements \\ Competing interests}

The authors have declared that no competing interests exist.

\section{Authors' contributions}

All authors contributed equally to this work.

\section{Funding information}

This research received no specific grant from any funding agency in the public, commercial or not-for-profit sectors.

\section{Data availability statement}

Data for this research are available upon request.

\section{Disclaimer}

The views and opinions expressed in this article are those of the authors and do not necessarily reflect the official policy or position of any affiliated agency of the authors.

\section{References}

Barrick, M.R., \& Mount, M.K. (1991). The Big Five personality dimensions and job performance: A meta-analysis. Personnel Psychology, 44(1), 1-26. https://doi. org/10.1111/j.1744-6570.1991.tb00688.x

Bakker, A.B., Tims, M., \& Derks, D. (2012). Proactive personality and job performance: The role of job crafting and work engagement. Human Relations, 65(10), 1359-1378. https://doi.org/10.1177/0018726712453471

Barrick, M.R., \& Mount, M.K. (1993). Autonomy as a moderator of the relationships between the big five personality dimensions and job performance. Journal of Applied Psychology, 78(1), 111-118. https://doi.org/10.1037/0021-9010.78.1.111

Beaty Jr, J.C., Cleveland, J.N., \& Murphy, K.R. (2001). The relation between personality and contextual performance in 'strong' versus 'weak' situations. Human Performance, 14(2), 125-148. https://doi.org/10.1207/S15327043HUP1402_01

Berdicchia, D., Nicolli, F., \& Masino, G. (2016). Job enlargement, job crafting and the moderating role of self-competence. Journal of Managerial Psychology, 31(2), 318-330.

Bell, C., \& Njoli, N. (2016). The role of big five factors on predicting job crafting propensities amongst administrative employees in a South African tertiary institution. SA Journal of Human Resource Management, 14(1), 1-11.

Brown, T. (2006). Confirmatory factor analysis for applied research. New York, NY Guildford.

Browne, M.W., \& Cudeck, R. (1993). Alternative ways of assessing model fit. In K.A Bollen \& J.S. Long (Eds.), Testing structural equation models (pp. 136-162) Newbury Park: Sage.

Borman, W.C., \& Motowidlo, S.J. (1997). Task performance and contextual performance: The meaning for personnel selection research. Human Performance, 10(2), 99-109. https://doi.org/10.1207/s15327043hup1002_3

Campbell, J.P. (1990). Modeling the performance prediction problem in industrial and organizational psychology. In M.D. Dunnette, \& L.M. Hough (Eds.), Handbook of industrial and organizational psychology (pp. 687-732). Consulting Psychologists Press.

Campbell, J.P., \& Wiernik, B.M. (2015). The modeling and assessment of work performance. Annual Review of Organizational Psychology and Organizational Behavior, 2(1), 47-74. https://doi.org/10.1146/annurev-orgpsych-032414-111427

Colbert, A.E., Mount, M.K., Harter, J.K., Witt, L.A., \& Barrick, M.R. (2004). Interactive effects of personality and perceptions of the work situation on workplace deviance. Journal of Applied Psychology, 89(4), 599-609. https://doi. org/10.1037/0021-9010.89.4.599

Culpepper, S.A., \& Aguinis, H. (2011). R is for revolution: A cutting-edge, free, opensource statistical package. Organizational Research Methods, 14(4), 735-740. https://doi.org/10.1177/1094428109355485

De Janasz, S.C., Dowd, K., \& Schneider, B. (2002). Interpersonal skills in organization. New York, NY: McGraw-Hill.

Demerouti, E., \& Bakker, A.B. (2014). Job crafting. In M.C.W. Peeters, J. de Jonge, \& T.W. Taris (Eds.), An introduction to contemporary work psychology (pp. 414-433). Chichester, UK: John Wiley \& Sons.

Demerouti, E., Bakker, A.B., \& Gevers, J.M. (2015). Job crafting and extra-role behavior: The role of work engagement and flourishing. Journal of Vocational Behavior, 91, 87-96. https://doi.org/10.1016/j.jvb.2015.09.001

Demerouti, E., Bakker, A.B., \& Halbesleben, J.R. (2015). Productive and counterproductive job crafting: A daily diary study. Journal of Occupational Health Psychology, 20(4), 457-469. https://doi.org/10.1037/a0039002

Demerouti, E., \& Rispens, S. (2014). Improving the image of student-recruited samples: A commentary. Journal of Occupational and Organizational Psychology, 87(1), 34-41. https://doi.org/10.1111/joop.12048

Digman, J.M. (1990). Personality structure: Emergence of the five-factor model. Annual Review of Psychology, 41(1), 417-440. https://doi.org/10.1146/annurev. ps.41.020190.002221

Dunn, T.J., Baguley, T., \& Brunsden, V. (2013). From alpha to omega: A practical solution to the pervasive problem of internal consistency estimation. British Journal of Psychology, 105(3), 399-412. https://doi.org/10.1111/bjop.12046

Ehrhart, K.H. (2006). Job characteristic beliefs and personality as antecedents of subjective person-job fit. Journal of Business and Psychology, 21(2), 193-226. https://doi.org/10.1007/s10869-006-9025-6

Furnham, A. (2002). Personality at work: Individual differences in the workplace: Person-organization-outcome fit. In B.W. Roberts \& R. Hogan (Eds.), Decade of behavior. Personality psychology in the workplace (pp. 223-251). Washington, DC: American Psychological Association. https://doi.org/10.4324/9780203134122

Fox, J., Nie, Z., \& Byrnes, J. (2012). Sem: Structural equation models. $R$ package version, 3.

Ghitulescu, B.E. (2006). Shaping tasks and relationships at work: Examining the antecedents and consequences of employee job crafting. Unpublished doctoral dissertation, Pittsburgh: University of Pittsburgh. 
Gordon, H.J., Demerouti, E., Le Blanc, P.M., \& Bipp, T. (2015). Job crafting and performance of Dutch and American health care professionals. Journal of Personnel performance of Dutch and American health care professionals. Journal of Per
Psychology, 14(4), 192-202. https://doi.org/10.1027/1866-5888/a000138

Goldberg, L.R. (1990). An alternative 'description of personality': The big-five factor structure. Journal of Personality and Social Psychology, 59(6), 1216-1229. https:// doi.org/10.1037/0022-3514.59.6.1216

Hoekstra, H. (1993). Work and personality. Paper presented at the 6th meeting of the International Society for the Study of Individual Differences, Baltimore, MD.

John, O.P., \& Srivastava, S. (1999). The big five trait taxonomy: History, measurement, and theoretical perspectives. In L.A. Pervin \& O.P. John (Eds.), Handbook of personality: Theory and research (2nd edn., pp. 102-138). New York, NY: Guilford Press.

Johnson, J.W., \& Schneider, R.J. (2013). Advancing our understanding of processes in personality-performance relationships. In N.D. Christiansen \& R.P. Tett (Eds.), Handbook of personality at work (pp. 30-52). New York, NY: Routledge.

Judge, T.A., \& Ilies, R. (2002). Relationship of personality to performance motivation A meta-analytic review. Journal of Applied Psychology, 87(4), 797-807. https:// doi.org/10.1037/0021-9010.87.4.797

Katz, D., \& Kahn, R.L. (1978). The social psychology of organizations (2nd edn.). New York, NY: Wiley.

Koopmans, L., Bernaards, C.M., Hildebrandt, V.H., Schaufeli, W.B., De Vet, H.C.W., \& Van Der Beek, A.J. (2011). Conceptual frameworks for individual work performance: A systematic review. Journal of Occupational and Environmental Medicine, 53(8), 856-866. https://doi.org/10.1097/JOM.0b013e318226a763

Leana, C., Appelbaum, E., \& Shevchuk, I. (2009). Work process and quality of care in early childhood education: The role of job crafting. Academy of Management Journal, 52(6), 1169-1192. https://doi.org/10.5465/amj.2009.47084651

Lichtenthaler, P., \& Fischbach, A. (2018). A meta-analysis on promotion- and prevention-focused job crafting. European Journal of Work and Organisationa Psychology, 28(1), 30-50. https://doi.org/10.1080/1359432X.2018.1527767

Marsh, H.W., Hau, K.T., \& Wen, Z. (2004). In search of golden rules: Comment on hypothesis-testing approaches to setting cutoff values for fit indexes and dangers in overgeneralizing $\mathrm{Hu}$ and Bentler's (1999) findings. Structural equation modeling, 11(3), 320-341.

McCrae, R.R., \& Costa Jr, P.T. (1992). Discriminant validity of NEO-PIR facet scales. Educational and Psychological Measurement, 52(1), 229-237.

McCrae, R.R., \& Costa, P.T. (1997). Personality trait structure as a human universal. American Psychologist, 52(5), 509-516. https://doi.org/10.1037/0003-066X. 52.5.509

McCrae, R.R., \& Costa, P.T., Jr. (2008). The five-factor theory of personality. In O.P. John, R.W. Robins, \& L.A. Pervin (Eds.), Handbook of personality: Theory and research (3rd edn., pp. 159-181). New York, NY: Guilford Press.

Motowidlo, S.J., \& Van Scotter, J.R. (1993). Evidence that task performance should be distinguished from contextual performance. Journal of Applied Psychology, 79(4), 475-480. https://doi.org/10.1037/0021-9010.79.4.475

Mount, M.K., Barrick, M.R., \& Stewart, G.L. (1998). Five-factor model of personality and performance in jobs involving interpersonal interactions. Human Performance, 11(2-3), 145-165. https://doi.org/10.1080/08959285. 1998.9668029

Norman, W.T. (1967). 2800 personality trait descriptors: Normative operating characteristics for a university population. Ann Arbor, MI: Michigan University. Retrieved n.d. from https://files.eric.ed.gov/fulltext/ED014738.pdf

Oldham, G.R., \& Hackman, J.R. (2010). Not what it was and not what it will be: The future of job design research. Journal of Organizational Behavior, 31(2-3), 463-479. https://doi.org/10.1002/job.678

Oldham, G.R., \& Fried, Y. (2016). Job design research and theory: Past, present and future. Organizational Behavior and Human Decision Processes, 136, 20-35. https://doi.org/10.1016/j.obhdp.2016.05.002

Ones, D.S., \& Viswesvaran, C. (2001). Personality at work: Criterion-focused occupational personality scales used in personnel selection. In B.W. Roberts \& R. Hogan (Eds.), Decade of behavior. Personality psychology in the workplace Hogan (Eds.), Decade of behavior. Personality psychology in the workplace
(pp. 63-92). Washington, DC: American Psychological Association. https://doi. (pp. 63-92). Washington,
org/10.1037/10434-003

Organ, D.W., \& Ryan, K. (1995). A meta-analytic review of attitudinal and dispositional predictors of organizational citizenship behavior. Personnel Psychology, 48(4), 775-802.

Organ, D.W. (1998). Organizational Citizenship Behavior: The Good Soldier Syndrome. Lexington, MA: Lexington Books.

Organ, D.W., Podsakoff, P.M., \& Podsakoff, N.P. (2011). Expanding the criterion domain to include organizational citizenship behavior: Implications for employe selection. In S. Zedeck (Ed.), APA handbook of industrial and organizational psychology: Selecting and developing members for the organization (Vol 2, pp. 281-324). Washington, DC: American Psychological Association. https://doi. org/10.1037/12170-010

Ozer, D.J., \& Benet-Martínez, V. (2006). Personality and the prediction of consequential outcomes. Annual Review of Psychology, 57, 401-421. https://doi.org/10.1146/ annurev.psych.57.102904.190127

Palaiou, K., Zarola, A., \& Furnham, A. (2016). The dark side of personality predicts positive and negative work attitudes. Personality and Individual Differences, 88 12-16. https://doi.org/10.1016/j.paid.2015.08.029
Podsakoff, P.M., MacKenzie, S.B., Lee, J.Y., \& Podsakoff, N.P. (2003). Common method biases in behavioral research: A critical review of the literature and recommended remedies. Journal of Applied Psychology, 88(5), 879-903. https://doi.org/10.1037/ remedies. Journal of

$\mathrm{R}$ Core Team (2016). R: A language and environment for statistical computing. Vienna, Austria: R Foundation for Statistical Computing. Retrieved from http://www. R-project.org/.

Revelle, W. (2016). Psych: Procedures for personality and psychological research. Evanston, IL: Northwestern University. Retrieved from https://cran.r-project.org/ web/packages/psych/index.htm

Rothmann, S., \& Coetzer, E.P. (2003). The big five personality dimensions and job performance. SA Journal of Industrial Psychology, 29(1), 68-74.

Rotundo, M., \& Sackett, P.R. (2002). The relative importance of task, citizenship, and counterproductive performance to global ratings of job performance: A policycapturing approach. Journal of applied psychology, 87(1), 66-80. https://doi. org/10.1037/0021-9010.87.1.66

Rosseel, Y. (2012). Lavaan: An R package for structural equation modeling and more. Version 0.5-12 (BETA). Journal of Statistical Software, 48(2), 1-36. Retrieved from https://biblio.ugent.be/publication/3099674.

Rudolph, C.W., Katz, I.M., Lavigne, K.N., \& Zacher, H. (2017). Job crafting: A metaanalysis of relationships with individual differences, job characteristics, and work outcomes. Journal of Vocational Behavior, 102, 112-138. https://doi. org/10.1016/j.jvb.2017.05.008

Saucier, G., \& Goldberg, L.R. (2003). The structure of personality attributes. In M.R. Barrick \& A.N. Ryan (Eds.), Personality and work: Reconsidering the role of personality in organizations (pp. 1-29). San Francisco, NC: Jossey-Bass.

Schreiber, J.B., Nora, A., Stage, F.K., Barlow, E.A., \& King, J. (2006). Reporting structural equation modeling and confirmatory factor analysis results: A review. The Journal of Educational Research, 99(6), 323-338. https://doi.org/10.3200/ JOER.99.6.323-338

Schumacker, R.E., \& Lomax, R.G. (2010). A Beginner's Guide to. Structural Equation Modeling (3rd edn.), New York: Taylor \& Francis Group.

Slemp, G.R., \& Vella-Brodrick, D.A. (2013). The Job Crafting Questionnaire: A new scale to measure the extent to which employees engage in job crafting. International Journal of Wellbeing, 3(2), 126-146. https://doi.org/10.5502/ijw.v3i2.1

Scollon, C.N., \& Diener, E. (2006). Love, work, and changes in extraversion and neuroticism over time. Journal of Personality and Social Psychology, 91(6), 11521165. https://doi.org/10.1037/0022-3514.91.6.1152

Taylor, N., \& de Bruin, G.P. (2006). Basic traits inventory: Technical manual. Johannesburg: Jopie van Rooyen \& Partners SA.

Tett, R.P., Jackson, D.N. \& Rothstein, M. (1991). Personality measures as predictors of job performance: A meta-analytic review. Personnel Psychology, 44(4), 703-742. https://doi.org/10.1111/j.1744-6570.1991.tb00696.x

Tims, M., Bakker, A.B., \& Derks, D. (2014). Daily job crafting and the self-efficacyperformance relationship. Journal of Managerial Psychology, 29(5), 490-507. https://doi.org/10.1108/JMP-05-2012-0148

Tims, M., Bakker, A.B., \& Derks, D. (2015). Job crafting and job performance: A longitudinal study. European Journal of Work and Organizational Psychology, 24(6), 914-928. https://doi.org/10.1080/1359432X.2014.969245

Tims, M., Bakker, A.B., Derks, D., \& Van Rhenen, W. (2013). Job crafting at the team and individual level: Implications for work engagement and performance. Group \& Organization Management, 38(4), 427-454. https://doi.org/10.1177/ 1059601113492421

Tims, M., \& Kooij, D. (2015). The active employee: Reconsidering the role of the individual worker in relation to the work context. In M. Van Veldhoven \& R. Pecce (Eds.), Well-being and performance at work: The role of context (pp. 112-128). Hove, UK: Psychology Press.

Tupes, E.C., \& Christal, R.E. (1961). Recurrent personality factors based on trait ratings. Journal of Personality, 60(2), 225-251. https://doi.org/10.1111/j.1467-6494.1992. tb00973.x

Van Scotter, J.R., \& Motowidlo, S.J. (1996). Interpersonal facilitation and job dedication as separate facets of contextual performance. Journal of Applied Psychology, 81(5), 525-531. https://doi.org/10.1037/0021-9010.81.5.525

Vogt, K., Hakanen, J.J., Brauchli, R., Jenny, G.J., \& Bauer, G.F. (2016). The consequences of job crafting: A three-wave study. European Journal of Work and Organizational Psychology, 25(3), 353-362. https://doi.org/10.1080/13594 32x.2015.1072170

Weseler, D., \& Niessen, C. (2016). How job crafting relates to task performance. Journal of Managerial Psychology, 31(3), 672-685.

Williams, L.J., \& Anderson, S.E. (1991). Job satisfaction and organizational commitment as predictors of organizational citizenship and in-role behaviors. Journal of Management, 17(3), 601-617. https://doi.org/10.1177/014920639101700305

Woods, S.A., \& Sofat, J.A. (2013). Personality and engagement at work: The mediating role of psychological meaningfulness. Journal of Applied Social Psychology, 43(11) 2203-2210. https://doi.org/10.1111/jasp.12171

Wrzesniewski, A., \& Dutton, J.E. (2001). Crafting a job: Revisioning employees as active crafters of their work. Academy of Management Review, 26(2), 179-201. https://doi.org/10.5465/amr.2001.4378011 